\title{
A clinical prediction rule for diagnosing human infections with avian influenza $A(H 7 N 9)$ in a hospital emergency department setting
}

Qiaohong Liao ${ }^{1 \dagger}$, Dennis K M Ip ${ }^{2 \dagger}$, Tim K Tsang ${ }^{3}$, Bin Cao ${ }^{4}$, Hui Jiang ${ }^{1}$, Fengfeng Liu', Jiandong Zheng ${ }^{1}$, Zhibin Peng ${ }^{1}$, Peng $\mathrm{Wu}^{3}$, Yang Huai ${ }^{5}$, Eric H Y Lau ${ }^{3}$, Luzhao Feng ${ }^{1}$, Gabriel M Leung ${ }^{2}$, Hongjie Yu ${ }^{1 *}$ and Benjamin J Cowling ${ }^{3}$

\begin{abstract}
Background: Human infections with avian influenza $A(H 7 N 9)$ virus are associated with severe illness and high mortality. To better inform triage decisions of hospitalization and management, we developed a clinical prediction rule for diagnosing patients with $\mathrm{A}(\mathrm{H} 7 \mathrm{~N} 9)$ and determined its predictive performance.

Methods: Clinical details on presentation of adult patients hospitalized with either $A(H 7 N 9)(n=121)$ in China from March to May 2013 or other causes of acute respiratory infections $(n=2,603)$ in Jingzhou City, China from January 2010 through September 2012 were analyzed. A clinical prediction rule was developed using a two-step coefficient-based multivariable logistic regression scoring method and evaluated with internal validation by bootstrapping.

Results: In step 1, predictors for A(H7N9) included male sex, poultry exposure history, and fever, haemoptysis, or shortness of breath on history and physical examination. In step 2, haziness or pneumonic consolidation on chest radiographs and leukopenia were also associated with a higher probability of $A(\mathrm{H} 7 \mathrm{~N} 9)$. The observed risk of $\mathrm{A}(\mathrm{H7N} 9)$ was $0.3 \%$ for those assigned to the low-risk group and 2.5\%,4.3\%, and $44.0 \%$ for tertiles 1 through 3, respectively, in the high-risk group. This prediction rule achieved good model performance, with an optimism-corrected sensitivity of 0.93 , a specificity of 0.80 , and an area under the receiver-operating characteristic curve of 0.96 .

Conclusions: A simple decision rule based on data readily obtainable in the setting of patients' first clinical presentations from the first wave of the A/H7N9 epidemic in China has been developed. This prediction rule has achieved good model performance in predicting their risk of $A(\mathrm{H} 7 \mathrm{~N} 9)$ infection and should be useful in guiding important clinical and public health decisions in a timely and objective manner. Data to be gathered with its use in the current evolving second wave of the A/H7N9 epidemic in China will help to inform its performance in the field and contribute to its further refinement.
\end{abstract}

Keywords: Avian influenza A(H7N9), Clinical prediction rule, Clinical diagnosis, Hospital emergency setting

\section{Background}

Human infections with novel avian-origin influenza A (H7N9) virus were first identified in March 2013, [1,2] mainly in the eastern provinces of China [3]. A total of 131 human infections, dominated by severe illness and mortality, were confirmed in the spring wave in mainland

\footnotetext{
*Correspondence: yuhj@chinacdc.cn

${ }^{\dagger}$ Equal contributors

'Division of Infectious Disease, Key Laboratory of Surveillance and Early-warning on Infectious Disease, Chinese Center for Disease Control and Prevention, 155\# Changbai Road, Beijing 102206, P.R. China

Full list of author information is available at the end of the article
}

China from March through May 2013 [4,5]. With the adoption of suitable public health measures including closure of live poultry markets, few cases were identified over the summer months [6]. However, H7N9 has resurged in this winter, 2013-2014 [7].

In the context of preparing and responding to further waves of this evolving epidemic, the importance of early detection, diagnosis, isolation and reporting of $\mathrm{A}(\mathrm{H} 7 \mathrm{~N} 9)$ infections has been repeatedly emphasized [8]. Accurate and objective risk prediction can help physicians to guide clinical management and inform triage decisions

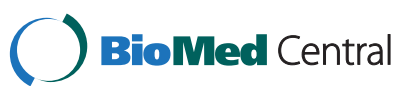

(c) 2014 Liao et al.; licensee BioMed Central Ltd. This is an Open Access article distributed under the terms of the Creative Commons Attribution License (http://creativecommons.org/licenses/by/4.0), which permits unrestricted use, distribution, and reproduction in any medium, provided the original work is properly credited. The Creative Commons Public Domain Dedication waiver (http://creativecommons.org/publicdomain/zero/1.0/) applies to the data made available in this article, unless otherwise stated. 
for optimizing the utilization of valuable clinical and public health resources that may easily be overwhelmed during an epidemic. However, no simple and reliable decision tool has yet been available for predicting the risk of $\mathrm{A}$ (H7N9) influenza in an objective and timely manner.

Our objective in this study was to develop a clinical prediction rule that would accurately identify patients with A(H7N9) influenza on their first presentation to a hospital emergency setting and to evaluate the predictive performance of this rule.

\section{Methods}

We analyzed two databases that contained clinical and basic laboratory data from two groups of patients presenting similarly with acute respiratory infections to hospitals in China, including 121 laboratory-confirmed A(H7N9) cases and 2,603 patients who suffered from acute respiratory infections other than $\mathrm{A}(\mathrm{H} 7 \mathrm{~N} 9)$ influenza. Outpatient clinics or emergency departments in hospitals represent a typical first step for patients with acute respiratory infections in China to present to the healthcare system, owing to the coverage of national health insurance programs and the lack of standalone primary healthcare clinics in either the public or private sector as an alternative [9].

The $\mathrm{A}(\mathrm{H} 7 \mathrm{~N} 9)$ database consisted of patients who presented clinically with symptoms of acute respiratory infection to hospitals in different provinces of China and were subsequently confirmed to have $\mathrm{A}(\mathrm{H} 7 \mathrm{~N} 9)$ virus infection between March and May 2013. In China, all laboratory-confirmed infections with $\mathrm{A}(\mathrm{H} 7 \mathrm{~N} 9)$ viruses are reported to the Chinese Center for Disease Control and Prevention (China CDC, Beijing, China) through a national surveillance system [10]. Diagnostic confirmation of $\mathrm{A}(\mathrm{H} 7 \mathrm{~N} 9)$ virus infection was done either by the isolation of $\mathrm{A}(\mathrm{H} 7 \mathrm{~N} 9)$ virus or a positive real-time reversetranscription polymerase chain reaction (RT-PCR) assay for $\mathrm{A}(\mathrm{H} 7 \mathrm{~N} 9)$ in a respiratory specimen [10]. Case definitions, surveillance for identification of influenza A(H7N9) cases, and laboratory test assays are described in previous reports [10].

The second database consisted of patients who presented similarly with acute respiratory infections to hospitals in Jingzhou city, Hubei province of China from 4 January 2010 through 30 September 2012. Their clinical details were captured by a surveillance program for severe acute respiratory infection (SARI) conducted by China CDC in four surveillance hospitals in Jingzhou during that period [11]. All patients admitted to these four surveillance hospitals were screened by either a nurse or physician. A patient was defined as having SARI if they had on their clinical presentation an elevated temperature (rectal or axillary temperature $\geq 37.3^{\circ} \mathrm{C}$ ) and at least one sign or symptom of acute respiratory illness, including cough, sore throat, tachypnea, difficulty breathing, abnormal breath sounds on auscultation, sputum production, hemoptysis, chest pain or chest radiograph consistent with pneumonia. Nasopharyngeal swabs were collected from these patients and tested for seasonal influenza and avian influenza $\mathrm{H} 5 \mathrm{~N} 1$ viruses by RT-PCR. As these samples were all collected before the first H7N9 human case was identified, they were not tested for $\mathrm{A}(\mathrm{H} 7 \mathrm{~N} 9)$ virus.

For patients included in either of these databases, clinical information on the medical history and physical examination findings on their initial clinical presentation was abstracted retrospectively from their original medical records using a standard data abstraction sheet by trained nursing and medical officers at each hospital. Patients younger than 14 years of age from both databases were not included in this study, as there are few patients $<14$ years of age with confirmed $\mathrm{A}(\mathrm{H} 7 \mathrm{~N} 9)$ virus infection, and their presenting symptoms, the approach of symptom ascertainment, overall clinical course and disease severity, disease epidemiology, and even health care seeking pattern and pathway were generally very different from that in adults and elderly persons [3-5].

Additional information collected included age, sex, history of any poultry exposure, including exposure to live poultry markets within two weeks of symptom onset, influenza vaccination history, smoking history, pregnancy, history of underlying medical conditions, height $(\mathrm{m})$, weight $(\mathrm{kg})$ and clinical symptoms.

The results of investigations performed on presentation included chest radiography (signs of consolidation and pneumonia), simple hematologic blood analysis including hemoglobin level ( $\mathrm{Hgb})$ and leukocyte count (WBC), and $\mathrm{C}$-reactive protein (CRP). Because we did not have sufficiently complete data $(>60 \%)$ on some laboratory determinations for the entire sample (including platelet count, other serum biochemistry tests and clotting profile), we excluded these determinations from the analysis for all patients.

\section{Ethics statement}

The collection of data from confirmed $\mathrm{A}(\mathrm{H} 7 \mathrm{~N} 9)$ cases was determined by the Chinese National Health and Family Planning Commission as part of public health investigations of emerging influenza outbreaks and was exempted from institutional review board assessment. Collection of data of SARI cases was approved by the ethical review committee of the China CDC. Therefore, informed consents from the cases were not required.

\section{Statistical analysis}

A two-step regression model was used to develop the prediction rule, so as to simulate the decision making process in the setting of a clinic or hospital emergency room where a patient first presents $[12,13]$. In step 1 , basic variables obtainable from the medical history and 
physical examination were employed to identify a subgroup of patients who were more likely to have A(H7N9) and, therefore, needed additional investigation and workup. Variables used in this stage included age group ( $<60$ years, $\geq 60$ years), sex, poultry exposure history, influenza vaccination history, smoking history, and history of underlying chronic diseases, pregnancy, major presenting symptoms and physical findings. In step 2, simple radiologic and laboratory variables were added to significant predictors from step 1 (those having a $P$-value less than 0.05 ) to further refine the identification of subgroups having higher risk for $\mathrm{A}(\mathrm{H} 7 \mathrm{~N} 9)$. We used a univariate logistic regression model to identify significant $(P \leq 0.05)$ predictors of a final diagnosis of $\mathrm{A}(\mathrm{H} 7 \mathrm{~N} 9)$ and then entered them into a multivariable logistic regression model with backward selection. We removed variables that had a $P$-value greater than 0.05 . Interaction terms were tested as candidate variables, but none of these terms entered the final models. We derived each prediction rule using all available information on patients. We used multiple imputations [14,15] (20 imputations) in the derivation process to make the most of all available non-missing data while preserving the uncertainty from the missing data in the results [16,17] [see Additional file 1: Appendix].

A score-based prediction rule for a final diagnosis of $\mathrm{A}$ (H7N9) was then developed for each step from the final logistic regression equations using a regression coefficientbased scoring method [13]. A simple integer-based point score was assigned for each predictor variable, which was calculated by dividing the corresponding $\beta$-coefficients by the absolute value of the smallest coefficient in the final model and rounding up to the nearest integer. The overall risk score for each patient was calculated by adding the scores for each component together [18]. Aiming to be used as a screening tool to capture as many of the A/H7N9 cases as possible, a cutoff was specified with a priori sensitivity of 0.99 in step 1 and 0.95 for the overall model (steps 1 and 2).

Total risk scores above the cutoff threshold were then categorized in tertiles as a risk prediction rule for ease of clinical implementation. Performance of the risk prediction rule in predicting $\mathrm{A}(\mathrm{H} 7 \mathrm{~N} 9)$ infection was examined by sensitivity, specificity, likelihood ratios for both positive and negative test results, and area under the receiveroperating characteristic (ROC) curve [19]. Calibration was evaluated by using the Hosmer-Lemeshow chi-square statistic ( $P>0.05$ for all models) [20]. Regression models were tested for possible overfitting by using linear shrinkage estimators $[13,21]$.

The prediction rule was internally validated with samples of the same size resampled with replacement from the original derivation data set using the bootstrap method [22]. The model was refitted as the original model derivation process on these bootstrap samples for 1,000 iterations $[13,21]$ to determine the degree of performance deterioration to be expected when applied on an independent sample of patients [21]. We also estimated the optimism-corrected estimates to correct for the absolute magnitude of bias for each performance index [23]. We performed all analyses with $\mathrm{R}$ software, version 3.0.1.

\section{Results}

As of the end of May 2013, 131 confirmed A(H7N9) cases were officially reported in mainland China. Among these patients, 121 patients of 14 years of age or older presenting with acute respiratory infection to an emergency department and requiring hospitalization for medical reasons were included in this study [5]. Two cases younger than 14 and eight cases having mild disease and confirmed by routine testing through sentinel influenzalike illness surveillance were excluded from the present study [9].

During the surveillance period from 4 January 2010 through 30 September 2012, 90,890 patients had been hospitalized in the four surveillance hospitals in Jingzhou city. Among these, 25,406 (28\%) patients met the SARI case definition within 24 hours of hospital admission. Ninety percent $(22,777)$ were $<14$ years of age and excluded from the present study. Among the 2,603 included patients, 2,310 (89\%) had a nasopharyngeal swab specimen collected, and 430 (19\%) tested positive for influenza viruses by rRT-PCR, including 258 (60\%) with influenza $\mathrm{A}(\mathrm{H} 3 \mathrm{~N} 2), 36$ (8\%) with $\mathrm{A}(\mathrm{H} 1 \mathrm{~N} 1)$ pdm09 and 136 (32\%) with influenza B.

Table 1 shows the demographic and clinical characteristics of these two groups of patients on presentation to the emergency hospital. On univariate analysis, factors that were associated with an increased risk of $\mathrm{A}(\mathrm{H} 7 \mathrm{~N} 9)$ infection included older age ( $\geq 60$ years), male sex, history of poultry exposure, smoking history, history of underlying medical conditions, fever, cough, haemoptysis, shortness of breath and diarrhea (Table 1). In step 1 of the clinical prediction rule, male sex and history of poultry exposure were independently associated with a final diagnosis of A(H7N9) on multivariable analysis. The presence of three respiratory symptoms, namely fever, haemoptysis and shortness of breath, were also independently associated with a final diagnosis of A(H7N9) (Table 2). Other factors became insignificant (age group, underlying medical illnesses, cough and diarrhea) and were not retained. Fifty-eight percent of the cohort with a total score less than the threshold of 43 was assigned to the low-risk group and did not proceed to step 2 [see Additional file 2: Figure S1].

In step 2, two additional laboratory findings including pneumonia/consolidation on chest radiograph and leukopenia (WBC <4,000/ $\mu \mathrm{l}$ ) were each independently associated with an increased risk of $\mathrm{A}(\mathrm{H} 7 \mathrm{~N} 9)$. On the other hand, finding of leukocytosis (WBC >11,000/ $\mu \mathrm{l}$ ), 
Table 1 Demographic and clinical characteristics of patients

\begin{tabular}{|c|c|c|c|}
\hline Characteristic & $\begin{array}{l}\text { H7N9 } \\
\text { (number = 121) }\end{array}$ & $\begin{array}{l}\text { Non-H7N9 } \\
\text { (number }=2,603 \text { ) }\end{array}$ & $P$-value \\
\hline \multicolumn{4}{|l|}{ Demographic } \\
\hline \multicolumn{4}{|l|}{ Age } \\
\hline 14 to 59 years & $50(41.3)$ & $1,293(49.7)$ & \multirow[t]{3}{*}{0.077} \\
\hline$\geq 60$ years & $71(58.7)$ & $1,310(50.3)$ & \\
\hline Data missing, \% & $0(0)$ & $0(0)$ & \\
\hline \multicolumn{4}{|l|}{ Sex } \\
\hline Female & $35(28.9)$ & $1,045(40.1)$ & \multirow[t]{3}{*}{0.013} \\
\hline Male & $86(71.1)$ & $1,558(59.9)$ & \\
\hline Data missing, $\%$ & $0(0)$ & $0(0)$ & \\
\hline \multicolumn{4}{|c|}{ History of poultry exposure } \\
\hline Yes & $85(70.2)$ & $53(2)$ & \multirow[t]{3}{*}{$<0.001$} \\
\hline No & $36(29.8)$ & $1,583(60.8)$ & \\
\hline Data missing, \% & $0(0)$ & $967(37.1)$ & \\
\hline \multicolumn{4}{|c|}{ Influenza vaccination history } \\
\hline Yes & $0(0)$ & $32(1.2)$ & \multirow[t]{3}{*}{0.999} \\
\hline No & $36(29.8)$ & $1,603(61.6)$ & \\
\hline Data missing, $\%$ & $85(70.2)$ & $968(37.2)$ & \\
\hline \multicolumn{4}{|l|}{ Smoking history } \\
\hline Yes & $26(21.5)$ & $365(14)$ & \multirow[t]{3}{*}{0.004} \\
\hline No & $78(64.5)$ & $2,238(86)$ & \\
\hline Data missing, $\%$ & $17(14)$ & $0(0)$ & \\
\hline \multicolumn{4}{|c|}{ History of underlying medical conditions } \\
\hline Yes & $42(34.7)$ & $846(32.5)$ & \multirow[t]{3}{*}{0.110} \\
\hline No & $62(51.2)$ & $1,751(67.3)$ & \\
\hline Data missing, \% & $17(14)$ & $6(0.2)$ & \\
\hline \multicolumn{4}{|c|}{ Presence of symptoms on presentation } \\
\hline Fever & $95(78.5)$ & $1,462(56.2)$ & \multirow[t]{2}{*}{$<0.001$} \\
\hline Data missing, $\%$ & $17(14)$ & $0(0)$ & \\
\hline Cough & $95(78.5)$ & $2,013(77.3)$ & \multirow[t]{2}{*}{$<0.001$} \\
\hline Data missing, $\%$ & $17(14)$ & $3(0.1)$ & \\
\hline Hemoptysis & $25(20.7)$ & $96(3.7)$ & \multirow[t]{2}{*}{$<0.001$} \\
\hline Data missing, $\%$ & $17(14)$ & $11(0.4)$ & \\
\hline Shortness of breath & $62(51.2)$ & $391(15)$ & \multirow[t]{2}{*}{$<0.001$} \\
\hline Data missing, \% & $17(14)$ & $9(0.3)$ & \\
\hline Sore throat & $7(5.8)$ & $418(16.1)$ & \multirow[t]{2}{*}{0.088} \\
\hline Data missing, $\%$ & $40(33.1)$ & $10(0.4)$ & \\
\hline Rhinorrhea & $2(1.7)$ & $131(5)$ & \multirow[t]{2}{*}{0.435} \\
\hline Data missing, \% & $40(33.1)$ & $9(0.3)$ & \\
\hline Vomiting & $4(3.3)$ & $67(2.6)$ & \multirow[t]{2}{*}{0.351} \\
\hline Data missing, \% & $17(14)$ & $9(0.3)$ & \\
\hline Diarrhea & $10(8.3)$ & $34(1.3)$ & \multirow[t]{2}{*}{$<0.001$} \\
\hline Data missing, \% & $17(14)$ & $9(0.3)$ & \\
\hline
\end{tabular}


Table 1 Demographic and clinical characteristics of patients (Continued)

\begin{tabular}{lll}
\hline Investigations & & \\
Chest radiography & $95(78.5)$ & $1,908(73.3)$ \\
Normal & $7(5.8)$ & $690(26.5)$ \\
Pneumonia/consolidation & $19(15.7)$ & $5(0.2)$ \\
Data missing, \% & & \\
Hemoglobin level & $20(16.5)$ & $903(34.7)$ \\
Low & $77(63.6)$ & $1,463(56.2)$ \\
Normal & $6(5)$ & $77(3)$ \\
High & $18(14.9)$ & $160(6.1)$ \\
Data missing, \% & & $201(7.7)$ \\
Leukocyte count & $48(39.7)$ & $1,567(60.2)$ \\
Low & $51(42.1)$ & $728(28)$ \\
Normal & $5(4.1)$ & $107(4.1)$ \\
High & $17(14)$ & 0.029 \\
Data missing, \% & & $192(7.4)$ \\
C-reactive protein & $8(6.6)$ & $1,025(39.4)$ \\
Normal & $83(68.6)$ & $1,386(53.2)$ \\
High & $30(24.8)$ & \\
Data missing, \% & & \\
\hline
\end{tabular}

or an abnormally low $(\mathrm{Hgb}<12 \mathrm{~g} / \mathrm{dl})$ or high hemoglobin level ( $\mathrm{Hgb} \geq 16 \mathrm{~g} / \mathrm{dl}$ ) were each independently associated with a decreased risk of $\mathrm{A}(\mathrm{H} 7 \mathrm{~N} 9)$. All of the previous five factors entered in step 1 had remained statistically significant after adding these two factors. No statistical evidence of overfitting, as demonstrated by linear shrinkage estimation (shrinkage factor, 0.981 (95\% confidence interval (CI), 0.976 to 0.984 ) for step 1 and 0.967 (95\% CI, 0.960 to

Table 2 Multivariable predicators of a diagnosis of A (H7N9) infection and associated risk scoring system for step 1

\begin{tabular}{lll}
\hline Characteristic & $\begin{array}{l}\boldsymbol{\beta} \text { regression coefficient } \\
(\mathbf{9 5 \%} \mathbf{~ C l})\end{array}$ & $\begin{array}{l}\text { Risk score } \\
\text { assigned }\end{array}$ \\
\hline $\begin{array}{ll}\text { Sex } \\
\text { Female }\end{array}$ & $\begin{array}{l}\text { Reference } \\
\text { Male } \\
\text { History of poultry exposure }\end{array}$ & 10 \\
Yes & $4.821(0.217,1.425)$ & \\
No & Reference & 52 \\
Presence of symptoms on presentation & 0 \\
Hemoptysis & $1.537(0.701,2.372)$ & 19 \\
Shortness of breath & $1.961(1.383,2.539)$ & 24 \\
Fever & $2.624(1.747,3.501)$ & 32 \\
\hline
\end{tabular}

Hosmer-Lemeshow statistic, $2.11(P=0.98)$. Cutoff threshold for total point score (with a prespecified sensitivity of 0.95 ): $\geq 43$ indicates high-risk groups; $<43$ indicates low-risk group. $\mathrm{Cl}$, confidence interval.
0.972) for step 2), was seen in either multivariable regression model. For the ease of use in a setting of a clinical consultation, the magnitude of association of each of these factors with $\mathrm{A}(\mathrm{H} 7 \mathrm{~N} 9)$ virus infection was quantified by a point scoring system as shown in Table 3. A total score of 68 or greater would indicate the presence of a high risk for $\mathrm{A}(\mathrm{H} 7 \mathrm{~N} 9)$ infection, with a prespecified sensitivity of $95 \%$ overall. Forty-five percent of patients considered in step 2 were further assigned to the low-risk category [see Additional file 2: Figure S1].

The magnitude of the scores had good diagnostic utility. When stratified by tertiles with the two cut-points of 70 and 90, a gradation with increasing level of risk for A (H7N9) infection was demonstrated. The corresponding risk of $\mathrm{A}(\mathrm{H} 7 \mathrm{~N} 9)$ infection was $0.3 \%$ (95\% CI, $0.0 \%$ to $0.6 \%$ ) for those assigned to the low-risk group (in steps 1 or 2 ), $2.5 \%$ ( $95 \% \mathrm{CI}, 0.5 \%$ to $4.5 \%$ ) for tertile 1 (risk score, 68 to 70 ), $4.3 \%$ (95\% CI, $2.2 \%$ to $6.4 \%$ ) for tertile 2 (risk score, 71 to 90 ) and $44.0 \%$ (95\% CI, $37.4 \%$ to $50.8 \%$ ) for tertile 3 (risk score >90) in the high-risk group. A similar gradation of risk was also observed in the validation analysis (Figure 1).

This clinical prediction rule achieved good discriminative ability. It gave a sensitivity of 0.93 and a specificity of 0.80 (optimism-corrected estimates) in the derivation process, which were broadly maintained, respectively, at 0.96 and 0.75 in the bootstrap internal validation process (Table 4). On the other hand, the optimism-corrected area 
Table 3 Multivariable predicators of a diagnosis of A(H7N9) infection and associated risk scoring system for step 2

\begin{tabular}{|c|c|c|}
\hline Characteristic & $\begin{array}{l}\beta \text { regression coefficient } \\
(95 \% \mathrm{Cl})\end{array}$ & $\begin{array}{l}\text { Risk score } \\
\text { assigned }\end{array}$ \\
\hline \multicolumn{3}{|l|}{ Sex } \\
\hline Female & Reference & 0 \\
\hline Male & $0.839(0.189,1.489)$ & 11 \\
\hline \multicolumn{3}{|l|}{ History of poultry exposure } \\
\hline Yes & $4.028(3.320,4.736)$ & 54 \\
\hline No & Reference & 0 \\
\hline \multicolumn{3}{|c|}{ Presence of symptoms on presentation } \\
\hline Hemoptysis & $1.107(0.109,2.105)$ & 15 \\
\hline Shortness of breath & $2.240(1.564,2.917)$ & 30 \\
\hline Fever & $2.769(1.790,3.748)$ & 37 \\
\hline \multicolumn{3}{|l|}{ Chest radiography } \\
\hline Normal & Reference & 0 \\
\hline Pneumonia/consolidation & $1.711(0.643,2.778)$ & 23 \\
\hline \multicolumn{3}{|l|}{ Leukocyte count } \\
\hline Low & $1.638(0.909,2.366)$ & 22 \\
\hline Normal & Reference & 0 \\
\hline High & $-1.581(-2.677,-0.485)$ & -21 \\
\hline \multicolumn{3}{|l|}{ Hemoglobin level } \\
\hline Low & $-0.884(-1.626,-0.143)$ & -12 \\
\hline Normal & Reference & 0 \\
\hline High & $-0.075(-1.739,1.590)$ & -1 \\
\hline
\end{tabular}

Hosmer-Lemeshow statistic, $3.57(P=0.89)$. Cutoff threshold for total point score (with a prespecified sensitivity of 0.95 ): $\geq 68$ indicates high-risk groups; $<68$ indicates low-risk group. $\mathrm{Cl}$, confidence interval.

under the ROC curve was 0.96 from both the derivation and the internal validation processes (Figure 2). Likelihood ratios for a positive result with an assignment to the highrisk group after step 2 were moderately strong at 4.62 and 3.85 for the derivation and internal validation processes, respectively. Likelihood ratios for a negative result with assignment to the low-risk group after step 1 or step 2 were 0.090 and 0.056 for the derivation and internal validation processes, respectively.

\section{Discussion}

Our study presents a decision rule for objectively predicting $\mathrm{A}(\mathrm{H} 7 \mathrm{~N} 9)$ infection in adult patients presenting with severe respiratory illness. Factors of particular importance in the prediction rule, including poultry exposure history, fever, shortness of breath and leukopenia, agreed generally with findings reported from previous epidemiological and clinical studies [4]. We had chosen the model with the best performance in terms of both the high sensitivity and area under the ROC curve, which were also maintained in the validation samples, to identify patients having a high risk for the infection at their initial



clinical presentation so as to optimize resources during an epidemic.

As generally recognized by previous reports, most laboratory-confirmed cases of A(H7N9) have had a high risk of disease progression and fatality [3,5]. Early initiation of antiviral treatment and provision of a suitable level of intensive care have been identified as important factors in determining the final outcome of patients hospitalized with $\mathrm{A}(\mathrm{H} 7 \mathrm{~N} 9)$ virus infection [24]. Our decision tool allows an initial risk assessment to be performed by frontline physicians in a setting where simple laboratory and radiographic examination may not be readily available, based only on simple information obtainable from the history and physical examination. In a setting with greater resources, the risk estimation of those deemed to have a non-trivial risk at step 1 could be further refined by the availability of simple radiographic and laboratory testing results. The scoring system also helps to categorize those being predicted as high-risk into different risk strata to facilitate further clinical decision-making (including the need for further work up, admission decision and ward allocation, initial treatment regimen, level of care and monitoring, and so on) before a definitive diagnosis based on RT-PCR can be available, often at a much later time. Despite the current belief that A(H7N9) virus may not be readily transmitted from person to person, $[3,10]$ the existence of limited person-to-person transmission in a close contact setting [25] also carries an implication for this risk stratification tool to better inform isolation decision and practice.

Depending on resource availability and surge capacity, patients assigned to different risk groups may need to be 
Table 4 Performance indices for the clinical prediction rule

\begin{tabular}{|c|c|c|c|}
\hline \multirow[t]{2}{*}{ Index } & \multicolumn{3}{|l|}{ Estimate $(95 \% \mathrm{Cl})$} \\
\hline & $\begin{array}{l}\text { Derivation indices } \\
(n=2,724)\end{array}$ & $\begin{array}{l}\text { Internal validation by } \\
\text { bootstrapping }(n=2,724)\end{array}$ & $\begin{array}{l}\text { Optimism-corrected } \\
\text { indices }(n=2,724)\end{array}$ \\
\hline Sensitivity & $0.940(0.895,0.984)$ & $0.958(0.890,0.994)$ & $0.929(0.881,0.954)$ \\
\hline Specificity & $0.799(0.783,0.815)$ & $0.751(0.614,0.885)$ & $0.799(0.783,0.815)$ \\
\hline \multicolumn{4}{|l|}{ Likelihood ratio } \\
\hline Positive test result & $4.670(4.124,5.309)$ & $3.853(2.570,7.747)$ & $4.624(3.986,4.887)$ \\
\hline Negative test result & $0.076(0.019,0.134)$ & $0.056(0.009,0.125)$ & $0.090(0.056,0.147)$ \\
\hline Area under ROC curve & $0.966(0.951,0.981)$ & $0.961(0.952,0.966)$ & $0.960(0.944,0.976)$ \\
\hline
\end{tabular}

Obtained from internal validation by using a bootstrap analysis in which the cohort was resampled 1,000 times with replacement.Likelihood ratio for a positive test result refers to the likelihood of assignment to the high-risk group after step 2 . Likelihood ratio for a negative test result refers to the likelihood of assignment to the low-risk group after steps 1 or 2 . Cl, confidence interval; ROC, receiver-operating characteristic.

handled differently. Generally, however, patients assigned to the low-risk group in either steps 1 or 2 should have little risk implication to justify their admission at that particular juncture either for monitoring or hospitalized care unless having other indications for admission. This strategy can help to reduce the demands on inpatient beds and testing capacity. On the other hand, persons having a total risk score exceeding the threshold $(\geq 68)$ in step 2 should be considered for admission for further assessment and possible initiation of treatment. The provision of different levels of monitoring and treatment to such patients could be guided by the magnitude of the total risk score, which is predictive of the eventual risk of confirmed $\mathrm{A}(\mathrm{H} 7 \mathrm{~N} 9)$ infection. Allocation of isolation facilities including individual negative-pressure isolation rooms may also be informed by the individual risk score

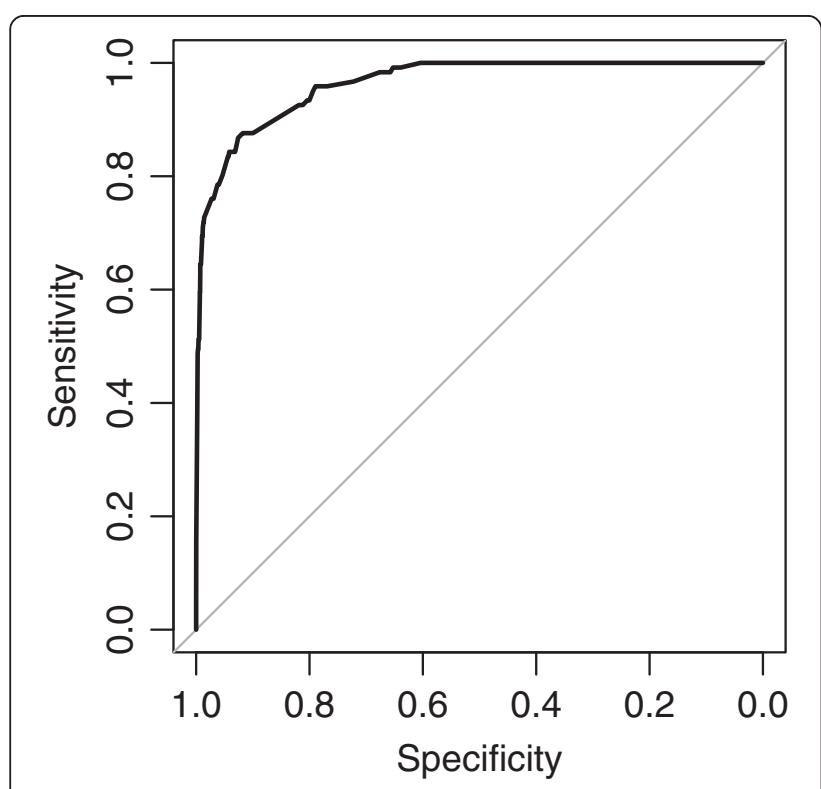

Figure 2 Receiver-operating characteristic (ROC) curve of the risk prediction rules with different pre-specified level of sensitivity. in case there is any enhancement in human-to-human transmissibility.

Our study included all cases of clinically confirmed A (H7N9) infection that presented with a picture of acute respiratory infection in a hospital setting in the first epidemic in China from March through May. Our control consisted of a suitable sample of patients who clinically presented in a comparable setting within the same geographical area and were captured by a large-scale surveillance network, in a period immediately prior to the A (H7N9) epidemic. Although controls had not been directly tested for $\mathrm{A}(\mathrm{H} 7 \mathrm{~N} 9)$ virus, their recruitment in a period during which human $\mathrm{A}(\mathrm{H} 7 \mathrm{~N} 9)$ infection was absent or at least very unlikely [26] should have helped to avoid their potential contamination by unascertained $\mathrm{A}(\mathrm{H} 7 \mathrm{~N} 9)$ cases.

However, our study does suffer from a number of potential limitations. First, as the H7N9 positive cases and the control patients were not gathered from exactly the same setting, subtle biases may still be introduced by potential variability in the degree of exposure ascertainment or data documentation in the two different settings. Although this problem should have been partly addressed by excluding any variables that were not measured or were generally missing from either group, some measured variables may have been more thoroughly ascertained for A(H7N9) cases, especially in an epidemic setting. Second, a small proportion of all confirmed $\mathrm{A}(\mathrm{H} 7 \mathrm{~N} 9)$ cases were either asymptomatic or only mildly symptomatic and had not been hospitalized [9]. Because of the very different clinical picture, our prediction rule may not be applicable for assessing the risk of $\mathrm{A}(\mathrm{H} 7 \mathrm{~N} 9)$ infection in this group of patients. Third, as our study had already included almost all confirmed cases of $\mathrm{A}(\mathrm{H} 7 \mathrm{~N} 9)$ reported during the initial epidemic in China, the decision rule could only be internally validated by bootstrapping but lacked a suitable sample for external validation. As a result, the actual performance and utility of this prediction rule in future epidemics remains to be determined. Ideally, our rule can be further validated in the current evolving second 
wave of epidemic in Chinawithin a setting where all cases presenting with acute respiratory infection (ARI) can be captured and ascertained with a definitive testing for A/H7N9 irrespective of their initial risk stratification status. This can inform the assessment of its performance in the field and contribute to its further refinement. Finally, as the prediction rule was derived mainly based on data of the A/H7N9 virus with little or no humanto-human transmission potential, its performance may become very different should the virus acquire the ability to do so. Other factors that may affect performance of the model in future waves of the evolving epidemic may include variation in disease severity, changing risk perception and health care seeking behavior. While the prediction of absolute risk for having $\mathrm{A}(\mathrm{H} 7 \mathrm{~N} 9)$ infection could be affected by variation in local factors, robustness of the model for separating higher from lower risk should probably be preserved. When being applied in the field, frontline physicians should remain alert concerning the potential limitations associated with practice guidelines and our decision rule should only supplement, but never supersede, the physician's judgment in equivocal or borderline cases.

\section{Conclusions}

Our prediction rule currently represents an important evidence-based decision tool for the triage of suspected cases of $\mathrm{A}(\mathrm{H} 7 \mathrm{~N} 9)$ infection when they first present clinically in an emergency department or primary care settings. This decision tool will be most useful in an evolving epidemic when the health system's surge capacity could be overwhelmed by the number of patients seeking care. With the current re-emergence of the A(H7N9) epidemic as the second wave in China, it would be a very timely and practical tool for helping both physicians working on the frontline to make important clinical decisions and public health professionals and health administrators to optimize the proper allocation of limited resources.

\section{Additional files}

Additional file 1: Appendix. Details on the multiple imputation and validation processes involved in building the risk prediction model [14-17,23].

Additional file 2: Figure S1. Flowchart of influenza $A(H 7 N 9)$ infection stratified by risk categories.

\section{Abbreviations}

China CDC: Chinese Center for Disease Control and Prevention; Cl: confidence interval; CRP: C-reactive protein; Hgb: hemoglobin; ROC: receiver-operating characteristic; RT-PCR: real-time reverse-transcription polymerase chain reaction; SARI: severe acute respiratory infection; WBC: leukocyte count.

\section{Competing interests}

DKMI reports receipt of research funding form Hoffmann-La Roche Inc. BJC reports receipt of research funding from Medlmmune Inc. and Sanofi Pasteur, and consults for Crucell NV. GML has received speaker honoraria from HSBC and CLSA. The authors report no other competing interests.

\section{Authors' contributions}

HY and DKMI designed and supervised the study. QL, HJ, FL, JZ, ZP, YH, LF, $B C, Z G$ and HY collected the data. QL, DKMI, TKT, HY, BJC, PW, EHYL and GML analyzed and interpreted the data. DKMI drafted the manuscript. All authors critically revised and approved the final manuscript.

\section{Acknowledgements}

We thank staff members of the Bureau of Disease Control and Prevention and Health Emergency Response Office of the National Health and Family Planning Commission and provincial and local departments of health for providing assistance with administration and data collection; staff members at county-, prefecture-, and provincial-level CDCs in the provinces where human A(H7N9) cases occurred for providing assistance with field investigation, administration and data collection. The views expressed are those of the authors and do not necessarily represent the policy of the China CDC.

\section{Funding}

This work was supported by the US National Institutes of Health (Comprehensive International Program for Research on AIDS grant U19 Al51915); the China-U.S. Collaborative Program on Emerging and Re-emerging Infectious Diseases, the Harvard Center for Communicable Disease Dynamics from the National Institute of General Medical Sciences (grant no. U54 GM088558) and the Area of Excellence Scheme of the Hong Kong University Grants Committee (grant no. AoE/M-12/06). The funding bodies had no role in study design, data collection and analysis, preparation of the manuscript, or the decision to publish.

\section{Author details}

${ }^{1}$ Division of Infectious Disease, Key Laboratory of Surveillance and Early-warning on Infectious Disease, Chinese Center for Disease Control and Prevention, 155\# Changbai Road, Beijing 102206, P.R. China. ${ }^{2}$ Division of Community Medicine and Public Health Practice, School of Public Health, Li Ka Shing Faculty of Medicine, The University of Hong Kong, Hong Kong Special Administrative Region, China. ${ }^{3}$ Division of Epidemiology and Biostatistics, School of Public Health, Li Ka Shing Faculty of Medicine, The University of Hong Kong, Hong Kong Special Administrative Region, China. ${ }^{4}$ Beijing Chao-Yang Hospital, Beijing Institute of Respiratory Medicine, Capital Medical University, Beijing, China. ${ }^{5}$ China-US Collaborative Program on Emerging and Re-emerging Infection Disease, US Centers for Disease Control and Prevention, Beijing, China.

Received: 20 February 2014 Accepted: 10 July 2014

Published: 5 August 2014

\section{References}

1. Gao R, Cao B, Hu Y, Feng Z, Wang D, Hu W, Chen J, Jie Z, Qiu H, Xu K, Xu X, Lu H, Zhu W, Gao Z, Xiang N, Shen Y, He Z, Gu Y, Zhang Z, Yang Y, Zhao X, Zhou L, Li X, Zou S, Zhang Y, Li X, Yang L, Guo J, Dong J, Li Q, et al: Human infection with a novel avian-origin influenza A (H7N9) virus. N Engl J Med 2013, 368:1888-1897.

2. Wu Y, Gao GF: Compiling of comprehensive data of human infections with novel influenza A (H7N9) virus. Front Med 2013, 7:275-276.

3. Cowling BJ, Jin L, Lau EH, Liao Q, Wu P, Jiang H, Tsang TK, Zheng J, Fang VJ, Chang Z, Ni MY, Zhang Q, Ip DK, Yu J, Li Y, Wang L, Tu W, Meng L, Wu JT, Luo H, Li Q, Shu Y, Li Z, Feng Z, Yang W, Wang $Y$, Leung GM, Yu H: Comparative epidemiology of human infections with avian influenza A H7N9 and H5N1 viruses in China: a population-based study of laboratory-confirmed cases. Lancet 2013, 382:129-137.

4. Gao HN, Lu HZ, Cao B, Du B, Shang H, Gan JH, Lu SH, Yang YD, Fang Q, Shen YZ, Xi XM, Gu Q, Zhou XM, Qu HP, Yan Z, Li FM, Zhao W, Gao ZC, Wang GF, Ruan LX, Wang WH, Ye J, Cao HF, Li XW, Zhang WH, Fang XC, He J, Liang WF, Xie J, Zeng M, et al: Clinical findings in 111 cases of influenza A (H7N9) virus infection. N Engl J Med 2013, 368:2277-2285.

5. Yu H, Cowling BJ, Feng L, Lau EH, Liao Q, Tsang TK, Peng Z, Wu P, Liu F, Fang VJ, Zhang H, Li M, Zeng L, Xu Z, Li Z, Luo H, Li Q, Feng Z, Cao B, Yang W, Wu JT, Wang Y, Leung GM: Human infection with avian influenza A H7N9 virus: an assessment of clinical severity. Lancet 2013, 382:138-145. 
6. Yu H, Wu JT, Cowling BJ, Liao Q, Fang VJ, Zhou S, Wu P, Zhou H, Lau EH, Guo D, Ni MY, Peng Z, Feng L, Jiang H, Luo H, Li Q, Feng Z, Wang Y, Yang W, Leung GM: Effect of closure of live poultry markets on poultry-to-person transmission of avian influenza A H7N9 virus: an ecological study. Lancet 2014, 383:541-548.

7. Chen E, Chen Y, Fu L, Chen Z, Gong Z, Mao H, Wang D, Ni MY, Wu P, Yu Z, He T, Li Z, Gao J, Liu S, Shu Y, Cowling BJ, Xia S, Yu H: Human infection with avian influenza $A(H 7 N 9)$ virus re-emerges in China in winter 2013. Euro Surveill 2013, 18:20616.

8. Gabbard JD, Dlugolenski D, Van Riel D, Marshall N, Galloway SE, Howerth EW, Campbell PJ, Jones C, Johnson S, Byrd-Leotis L, Steinhauer DA, Kuiken T, Tompkins SM, Tripp R, Lowen AC, Steel J: Novel H7N9 influenza virus shows low infectious dose, high growth and efficient contact transmission in the guinea pig model. J Virol 2014, 88:1502-1512.

9. Ip DK, Liao Q, Wu P, Gao Z, Cao B, Feng L, Xu X, Jiang H, Li M, Bao J, Zheng J, Zhang Q, Chang Z, Li Y, Yu J, Liu F, Ni MY, Wu JT, Cowling BJ, Yang W, Leung $\mathrm{GM}$, Yu H: Detection of mild to moderate influenza A/H7N9 infection by China's national sentinel surveillance system for influenza-like illness: case series. BMJ 2013, 346:\{3693.

10. Li Q, Zhou L, Zhou M, Li F, Wu H, Xiang N, Chen E, Tang F, Wang D, Meng L, Hong Z, Tu W, Cao Y, Li L, Ding F, Liu B, Wang M, Xie R, Gao R, Li X, Bai T, Zou S, He J, Hu J, Xu Y, Chai C, Wang S, Gao Y, Jin L, Zhang Y, et al: Preliminary report: epidemiology of the avian influenza A (H7N9) outbreak in China. N Engl J Med 2014, 370:520-532.

11. Yu H, Huang J, Huai Y, Guan X, Klena J, Liu S, Peng Y, Yang H, Luo J, Zheng J, Chen M, Peng Z, Xiang N, Huo X, Xiao L, Jiang H, Chen H, Zhang Y, Xing X, Xu Z, Feng Z, Zhan F, Yang W, Uyeki TM, Wang Y, Varma JK: The substantial hospitalization burden of influenza in central China: surveillance for severe, acute respiratory infection, and influenza viruses, 2010-2012. Influenza Other Respir Viruses 2014, 8:53-65.

12. Fine MJ, Auble TE, Yealy DM, Hanusa BH, Weissfeld LA, Singer DE, Coley CM, Marrie TJ, Kapoor WN: A prediction rule to identify low-risk patients with community-acquired pneumonia. N Engl J Med 1997, 336:243-250.

13. Leung GM, Rainer TH, Lau FL, Wong IO, Tong A, Wong TW, Kong JH, Hedley AJ, Lam TH, Hospital Authority SARS Collaborative Group: A clinical prediction rule for diagnosing severe acute respiratory syndrome in the emergency department. Ann Intern Med 2004, 141:333-342.

14. Schafer JL: Multiple imputation: a primer. Stat Methods Med Res 1999, 8:3-15.

15. Harrell FE Jr: Regression Modeling Strategies: With Applications to Linear Models, Logistic Regression, and Survival Analysis. New York: Springer Verlag; 2001.

16. Little RJ, Rubin DB: Statistical Analysis with Missing Data. 2nd edition. Hoboken, NJ: Wiley; 2002.

17. Rubin DB: Multiple imputation after 18+ years. J Am Stat Assoc 1996 91:473-489.

18. Sullivan LM, Massaro JM, D'Agostino RB Sr: Presentation of multivariate data for clinical use: The Framingham Study risk score functions. Stat Med 2004, 23:1631-1660.

19. Hanley JA, McNeil BJ: The meaning and use of the area under a receiver operating characteristic (ROC) curve. Radiology 1982, 143:29-36.

20. Hosmer DW, Lemeshow S: Applied Logistic Regression. 2nd edition. New York: Wiley; 2000

21. Lee DS, Austin PC, Rouleau JL, Liu PP, Naimark D, Tu JV: Predicting mortality among patients hospitalized for heart failure: derivation and validation of a clinical model. JAMA 2003, 290:2581-2587.

22. Efron B, Tibshirani RJ: An Introduction to the Bootstrap. Chapman \& Hall/CRC Pr; 1998.

23. Harrell FE Jr, Lee KL, Mark DB: Multivariable prognostic models: issues in developing models, evaluating assumptions and adequacy, and measuring and reducing errors. Stat Med 1996, 15:361-387.

24. Yu L, Wang Z, Chen Y, Ding W, Jia H, Chan JF, To KK, Chen H, Yang Y, Liang W, Zheng S, Yao H, Yang S, Cao H, Dai X, Zhao H, Li J, Bao Q, Chen P, Hou $X$, Li L, Yuen KY: Clinical, virological, and histopathological manifestations of fatal human infections by avian influenza $A(H 7 N 9)$ virus. Clin Infect Dis 2013, 57:1449-1457.
25. Qi X, Qian YH, Bao CJ, Guo XL, Cui LB, Tang FY, Ji H, Huang Y, Cai PQ, Lu B, Xu K, Shi C, Zhu FC, Zhou MH, Wang H: Probable person to person transmission of novel avian influenza A (H7N9) virus in Eastern China, 2013: epidemiological investigation. BMJ 2013, 347:f4752.

26. Bai T, Zhou J, Shu Y: Serologic study for influenza A (H7N9) among high-risk groups in China. N Engl J Med 2013, 368:2339-2340.

doi:10.1186/s12916-014-0127-0

Cite this article as: Liao et al:: A clinical prediction rule for diagnosing human infections with avian influenza $A(H 7 N 9)$ in a hospital emergency department setting. BMC Medicine 2014 12:127.

\section{Submit your next manuscript to BioMed Central and take full advantage of:}

- Convenient online submission

- Thorough peer review

- No space constraints or color figure charges

- Immediate publication on acceptance

- Inclusion in PubMed, CAS, Scopus and Google Scholar

- Research which is freely available for redistribution

Submit your manuscript at www.biomedcentral.com/submit
C) Biomed Central 